\title{
Mentorship Program in Medical College: An Effective Tool in Medical Education
}

\author{
Amrith Pakkala ${ }^{1}$, Ashwini K Shetty ${ }^{2 *}$ \\ ${ }^{1}$ Dept of Physiology, Shridevi Institute of Medical Sciences \& Research Hospital, Tumakuru, Karnataka, India \\ ${ }^{2}$ Dept of Physiology, MVJ Medical College \& Research Hospital, Hoskote, Karnataka, India
}

\begin{abstract}
Background: Mentoring is an effective tool to provide necessary guidance to a new student on his or her entry to a professional course.

It is important to know the students' felt needs in order to have a useful mentorship program. Research confirms that quality mentoring relationships have powerful positive effects on young people in a variety of personal, academic, and professional situations. This study was conducted to gauge the felt needs of a first MBBS student regarding mentorship program in the light of their previous exposure to such a program already conducted. It was intended to understand the needs of specialist mentors during the course of the student life.

Material And Methods: The Thrive Questionnaire designed by the University of Central Missouri, CA, USA was administered to 50 students who had recently completed the first MBBS training program and are already exposed to mentorship program.

Results: Most of the students (95\%) responded with a score of above average level of satisfaction on all parameters classified as life parameters. Relating well with others, professional advancement and relating meaningfully with local people were the preferred answers to the extent of $90 \%$ of the sample studied. Among the three general kinds of mentors, friend or peer mentor, general mentor and specialist mentor, students most of the time preferred friend or peer type.

Conclusion: Mentoring provides critical guidance to a young person on his or her path to success. But if one in three young people are reaching adulthood without a mentor, that means too many of these impactful relationships are being left to chance. We must develop and strengthen systems that identify young people most in need of a mentor and least likely to have a mentor, determine their mentoring needs and match them with quality mentors and services to meet those needs.
\end{abstract}

Keywords: Mentor, First MBBS, Medical Education

\section{Introduction}

Mentorship program is aimed at fostering growth among students in many areas of life. Mentoring, at its core, guarantees young people that there is someone who cares about them, assures them they are not alone in dealing with day-to-day challenges, and makes them feel like they matter. It is important to know the students' felt needs in order to have a useful mentorship program. Research confirms that quality mentoring relationships have powerful positive effects on young people in a variety of personal, academic, and professional situations. Ultimately, mentoring connects a young person to personal growth and development, and social and economic opportunity. Yet one in three young people will grow up without this critical asset.

\section{Material \& Methods}

This study was conducted to gauge the felt needs of a first MBBS student regarding mentorship program in the light of their previous exposure to such a program already conducted. It was intended to understand the needs of specialist mentors during the course of the student life.
The specific objectives of this study were:

1. Discover areas where mentoring may be useful

2. Consider the different type of mentor that could be available

3. Usefulness of mentoring relationship to stimulate personal growth

The Thrive Questionnaire designed by the University of Central Missouri, CA, USA was administered to 50 students who had recently completed the first MBBS training program and are already exposed to mentorship program.

\section{Results:}

The following questions were posed in the questionnaire administered:

1. How satisfied are you with the following areas of your life? Physical strength and stamina, Intellectual, Relationships and family, Spiritual, Main work, Life overall 
Most of the students $(95 \%)$ responded with a score of above average level of satisfaction on all these parameters.

2. Question related to aspect of life and category of life where some guidance, training and or encouragement was need:

The answers varied from, handling major transitions, victory over temptations to maintain body weight respectively in the category of life planning, spiritual and physical parameters

On the intellectual, emotional, relationships \& family, profession and cultural adaptation fronts, language and cultural competence, freedom from anxieties. Relating well with others, professional advancement and relating meaningfully with local people were the preferred answers to the extent of $90 \%$ of the sample studied.

3. Question on what way one would like to be helped:

Listening, providing growth opportunities and teaching specific skills was the majority reply in $92 \%$ of the sample studied.

Among the three general kinds of mentors, friend or peer mentor, general mentor and specialist mentor, students most of the time preferred friend or peer type.

4. On the specialist type of mentors majority preferred the medical doctor, the psychologist, the trainer, and the orientation mentor.

5. All general mentors and peer mentors were found to be on equal footing in the opinion of the study group.

6. Personalities of mentors preferred was best related to intellectual and one who would follow a clear plan rather than a serious type or one who would give advice.

The success of a mentoring relation sip was felt equally in all parameters tested that is motivated to learn and develop, willing to commit time, willing to work on growth and development, willing to be open and honest and willing to receive critical feedback. This shows that the group will benefit greatly from a mentoring relationship.

7. On the approach which would work best for the mentors, it was felt that asking someone known or recommended by the mentor giving various options to ensure that the mentor is suitable.

\section{Discussion}

Medical students today are faced with an increasingly challenging environment.

Mentoring has significant positive effects on two early warning indicators that a student may be falling off-track:
High levels of absenteeism ${ }^{[1]}$

Students who meet on healthy ambient regularly with their mentors are $52 \%$ less likely than their peers to skip a day of school and $37 \%$ less likely to skip a class. ${ }^{[2]}$

Recurring behavior problems ${ }^{[3]}$

Young adults who face an opportunity gap but have a mentor are $55 \%$ more likely to be enrolled in college than those who did not have a mentor. ${ }^{[4]}$

- In addition to better school attendance and a better chance of going on to higher education, mentored youth maintain better attitudes toward school. ${ }^{[5]}$

- By being a consistent adult presence in a young person's life mentors can offer advice, share life their experiences, and help a young person navigate challenges.

- Youth who meet regularly with their mentors are:

- $\quad 46 \%$ less likely than their peers to start using illegal drugs and $27 \%$ less likely to start drinking. ${ }^{[2]}$

- Young adults who face an opportunity gap but have a mentor are: $\mathbf{8 1} \%$ more likely to participate regularly in sports or extracurricular activities than those who do not. ${ }^{[6]}$

- A study showed that the strongest benefit from mentoring, and most consistent across risk groups, was a reduction in depressive symptoms particularly noteworthy given that almost one in four youth reported worrisome levels of these symptoms at baseline. ${ }^{[3]}$

- Mentoring promotes positive social attitudes and relationships. Mentored youth tend to trust their parents more and communicate better with them. ${ }^{[3]}$

One study estimates that the human potential lost as a result of the educational achievement gap is the economic equivalent of a permanent national recession. ${ }^{[6]} \mathrm{By}$ preparing young people for college and careers, mentoring helps develop the future workplace talent pipeline. ${ }^{6}$ Mentors can also prepare their mentees for professional careers and assist with their workplace skills by:

- Helping set career goals and taking the steps to realize them.

- Using personal contacts to help young people network with industry professionals, find internships, and locate possible jobs.

- Introduce young people to resources and organizations they may not be familiar with.

- Skills for seeking a job, interviewing for a job, and keeping a job. 
The number of ways mentoring can help a young person are as varied as the people involved in each program. While the lists and statistics can be impressive, personal stories can be even more impressive. Take a look at some mentoring success stories to see the impact of mentoring in real life.

The findings of the report commissioned by MENTOR: The National Mentoring Partnership with support from AT\&T, and written by Civic Enterprises in partnership with Hart Research are consistent with a powerful mentoring effect as demonstrated by the life experiences of the young people surveyed and mentioning's link to improved academic, social and economic prospects. This mentoring effect is growing and, if harnessed, it has the potential to help meet a range of national challenges and strengthen our communities and economy.

The survey found that 1.8 million at-risk young adults had been matched in mentoring relationships through mentoring programs while they are growing up. In the early 1990s an estimated 300,000 at-risk young people had a structured mentoring relationship. Another 4.1 million at-risk young adults had informal mentoring relationships with teachers, coaches, extended family members or neighbors while they were growing up.

Despite this positive trend, one in three young people surveyed did not have a mentor while they were growing up. Applying their experiences to the U.S. Census demographics for 8-18 year olds, it is projected that 16 million young people, including 9 million at-risk young people, will reach adulthood without connecting with a mentor of any kind.

The survey also showed that with each additional risk factor a young person experiences, the less likely he or she is to connect with an informal mentor. This finding suggests a systemic shift to leverage quality mentoring programs to introduce mentors to young people who face a greater number of risk factors is a powerful and necessary strategy.

The experiences of the young people surveyed showed significant positive outcomes for those who had a mentor. At-risk young people with mentors were more likely to aspire to attend and to enroll in college. They were more likely to report participating in sports and other extracurricular activities. They also were more likely to report taking leadership roles in school and extracurricular activities and to regularly volunteer in their communities.

With input from industry stakeholders and thought-leaders, the report outlines opportunities for the public, private and philanthropic sectors to systemically integrate mentoring as a key youth development strategy. The report describes a series of paths forward that would lead to a society where all young people have access to a quality mentoring relationship and the support they need to succeed in school, work and life.

\section{Conclusion}

When mentoring is integrated into research-based reforms and interventions it can strengthen efforts to reduce poverty, truancy, drug abuse and violence, while promoting healthy decision-making, positive behaviors and activities and academic achievement.

Mentoring provides critical guidance to a young person on his or her path to success. But if one in three young people are reaching adulthood without a mentor, that means too many of these impactful relationships are being left to chance. We must develop and strengthen systems that identify young people most in need of a mentor and least likely to have a mentor, determine their mentoring needs and match them with quality mentors and services to meet those needs.

Incorporate mentoring into public policies and programs that promote education, youth development, and community service, and raise and allocate funding to mentoring programs.

The broad interpretation of "mentoring" in public policies and funding programs can lead to inconsistent quality and uneven results. The private sector is uniquely positioned to strengthen the mentoring effort, with financial and human resources available and a strong business interest in developing tomorrow's workforce. Companies can offer employees paid time off to volunteer, financially support external mentoring programs and set corporate mentoring goals. In return, they can see increased employee productivity, improved morale and retention, and improved public image and community relations.

With the mentoring field's increasingly robust research and practice base, it is important to strengthen the feedback loop between these two communities to more efficiently and effectively close the mentoring gap.

Technology and youth-initiated mentoring are two examples of innovations that have the potential to dramatically increase the supply of mentors.

\section{References}

1. Kennelly L, Monrad M - Approaches to Dropout Prevention: Heeding Early Warning Signs with Appropriate Interventions. American Institutes for Research, 2007

2. JP Tierney - Making a Difference.An Impact Study of Big Brothers/Big Sisters. ERIC 1995

3. Thurlow ML, SinclairMF, Johnson DF -Students with Disabilities Who Drop Out of School: Implications for Policy 
and Practice. Issue Brief: Examining Current Challenges in Secondary Education, 2002

4. Bruce M, Bridgeland J - The mentoring effect: Young people>s perspectives on the outcomes and availability of mentoring. Washington, DC: Civic Enterprises with Hart, 2014
5. Herrera C, DuBois DL, Grossman JB - The Role of Risk: Mentoring Experiences and Outcomes for Youth with Varying Risk Profiles. MDRC, 2013

6. Wear II PW, Wilson LL -Bridging the great divide Educational Entrepreneurship, 2015

*Corresponding author:

Dr. Ashwini K Shetty, MD Associate Professor, Dept of Physiology, MVJ Medical College \& Research Hospital, Hoskote, Karnataka, India

Email: pan1832@gmail.com

Financial or other Competing Interests: None.

http://www.aamsjournal.com 